\title{
Article \\ Control-Oriented Characterization of Product Properties during Hot Hole-Flanging of X46Cr13 Sheet Material in a Progressive-Die
}

\author{
Juri Martschin ${ }^{1, *(\mathbb{D}}$, Rickmer Meya ${ }^{1}\left(\mathbb{D}\right.$, Daniel Klöser $^{2}\left(\mathbb{D}\right.$, Thomas Meurer $^{2}\left(\mathbb{D}\right.$ and A. Erman Tekkaya ${ }^{1}$ \\ 1 Institute of Forming Technology and Lightweight Components (IUL), TU Dortmund University, \\ Baroper Str. 303, 44227 Dortmund, Germany; Rickmer.meya@iul.tu-dortmund.de (R.M.); \\ Erman.Tekkaya@iul.tu-dortmund.de (A.E.T.) \\ 2 Chair of Automatic Control, Kiel University, Kaiserstraße 2, 24143 Kiel, Germany; \\ dkl@tf.uni-kiel.de (D.K.); tm@tf.uni-kiel.de (T.M.) \\ * Correspondence: juri.martschin@iul.tu-dortmund.de; Tel.: +49-0231-755-8437
}

check for updates

Citation: Martschin, J.; Meya, R.; Klöser, D.; Meurer, T.; Tekkaya, A.E. Control-Oriented Characterization of Product Properties during Hot Hole-Flanging of X46Cr13 Sheet Material in a Progressive-Die. Metals 2021, 11, 349. https://doi.org/ $10.3390 /$ met11020349

Academic Editors: Badis Haddag and Tudor Balan

Received: 25 January 2021

Accepted: 16 February 2021

Published: 19 February 2021

Publisher's Note: MDPI stays neutral with regard to jurisdictional claims in published maps and institutional affiliations.

Copyright: (c) 2021 by the authors. Licensee MDPI, Basel, Switzerland. This article is an open access article distributed under the terms and conditions of the Creative Commons Attribution (CC BY) license (https:/ / creativecommons.org/licenses/by/ $4.0 /)$.

\begin{abstract}
Robust and versatile production is enabled by a closed-loop control of product properties. This essentially relies on the characterization of the interaction between properties and available degrees of freedom to control the process. In particular, this work examines the setting of collar height, thinning, curvature, and hardness during hot hole-flanging of $\mathrm{X} 46 \mathrm{Cr} 13$ sheet material with simultaneous heat treatment to identify approaches for a closed-loop property control in hot holeflanging during multi-stage hot sheet metal forming. To scrutinize the adjustability of the hardness of $\mathrm{X} 46 \mathrm{Cr} 13$ sheet material by heat treatment with rapid heating and short dwell times, quenching tests with austenitizing temperatures from 900 to $1100{ }^{\circ} \mathrm{C}$ and dwell times from 1 to $300 \mathrm{~s}$ were carried out. A hardness between 317 and 680 HV10 was measured. By analyzing the force-displacement curve and the contact situation between tools and blank during hot hole-flanging, an understanding for the process was established. To determine the adjustability of geometrical collar properties and the hardness of the collar, collars were formed at punch speeds between 5 and $100 \mathrm{~mm} / \mathrm{s}$ and at different temperatures. Here, a dependency of the geometry of the collar on temperature and punch speed as well as setting of the hardness was demonstrated.
\end{abstract}

Keywords: hole-flanging; product properties; press hardening; progressive-die; hot forming; process control; closed-loop control; martensitic chromium steel; X46Cr13

\section{Introduction}

Hot sheet metal forming by multiple consecutive forming operations combined with press hardening in multi-stage tools enables the production of hardened components while facilitating advanced shaping capabilities [1]. An implementation of a progressive-die hot stamping process for producing automobile seat belt buckles [2] and a progressive-die plate forging of tailored high strength gear parts [3] was realized. However, even within a single press hardening stage, the thermal and mechanical interactions are complex to assess [4]. Still, the realization of a zero-defect production represents one of the major challenges in press hardening [5]. Hence, to deduct a functional process window for a process chain with multiple consecutive hot forming steps requires extensive modelling [6]. The targeted setting or, moreover, the batch-dependent variation of product properties therefore represents an additional challenge. To allow for a robust and versatile production in forming processes, a closed loop control can be employed [7]. Here, process variables and product properties are measured, fed back to the system by means of a controller, and set by variation of process parameters using real-time capable models. First approaches for a sole closed-loop control of springback [8], microstructure [9] or strength [10] in hot sheet metal bending in a progressive-die were developed. 
From a systems and control perspective, controllability and observability are key enablers for the design of property-related control concepts. Loosely speaking, the term controllability refers to the availability of a suitable number of degrees of freedom (inputs) such as temperature, process speed, dwell time, holding pressure, or other press related parameters to eventually adjust the thermo-plastic process in a desired way. Observability addresses the ability to reconstruct the in general spatial-temporal process evolution based on the availability of appropriate sensor data in conjunction with a process model. Controllability and observability are intrinsically interconnected with actuator and sensor selection and placement and give rise to the need to identify and control the interaction between the available inputs, the sensory outputs, and the product properties. This, however, requires adequate control-oriented process models capturing the process dynamics combined with the characterization of the product properties depending on the process evolution and the input history.

As one of the essential steps towards the development of fundamental approaches for the property control in multi-step hot forming process, hot hole-flanging is investigated in this work, whereby the boundary conditions given by an implementation in multistage forming within a progressive-die are considered. During hole-flanging, a punch is moved into a pre-hole in a sheet. With progressing punch-feed, the hole is expanded and the material folds sideways around the punch. Optionally, a blank holder is used. In temperature-assisted hole-flanging or hot hole-flanging, the sheet is additionally heated either during or before forming. This allows for the expansion of process limits and a simultaneous heat treatment. Groche and Erhardt [11] demonstrate an enhancement of the expansion ratio during laser assisted warm $\left(\sim 200^{\circ} \mathrm{C}\right)$ hole-flanging of magnesium and aluminum sheets as well as a difference in strain hardening between the inner and the outer surface of the collar. Motaman et al. [12] improved the expansion ratio during laser-assisted warm $\left(\sim 250^{\circ} \mathrm{C}\right.$ to $\left.400{ }^{\circ} \mathrm{C}\right)$ hole-flanging of DP1000 sheet material in a progressive-die by taking advantage of dynamic strain aging. Cheng [13] developed a one-step hot stampingforging method that enables the hole-flanging of high strength quenchable steel sheet 15B22. Despite the ongoing research, a control-oriented analysis of the relationships between the product properties and the process parameters during hot hole-flanging with simultaneous heat treatment is not known. Likewise, the force-displacement curve during hot hole-flanging and its implementation in process control has not yet been assessed. To derive approaches for a control of product properties, knowledge of these yet unknown relationships is required.

In this contribution, influences of process parameters on the product properties during hot hole-flanging of $\mathrm{X} 46 \mathrm{Cr} 13$ sheet material within the frame of closed-loop controlled multi-stage forming in a progressive-die are revealed. In particular, the influence of the austenitization parameters and the punch speed on the geometry of the collar (thickness, curvature) and the hardness distribution are analyzed. The adjustability of $\mathrm{X} 46 \mathrm{Cr} 13$ sheet material hardness by rapid heating and quenching is examined. Hot hole-flanging tests are carried out where the force-displacement curve as well as geometric properties and the hardness of the formed collar are analyzed. The relationships revealed results in approaches for a closed-loop control of product properties during hot hole-flanging, which is applicable in multi-stage hot sheet metal forming. As a matter of convenience, Table 1 represents the nomenclature of this paper. 
Table 1. Nomenclature.

\begin{tabular}{lll}
\hline$\alpha_{\mathrm{P}}$ & Cone angle of the punch & {$\left[{ }^{\circ}\right]$} \\
$\kappa_{\mathrm{c}}$ & Curvature of the collar & {$[1 / \mathrm{mm}]$} \\
$\kappa_{\mathrm{c}, \mathrm{ou}}$ & Curvature along the outer developed length of the collar & {$[1 / \mathrm{mm}]$} \\
$D_{\mathrm{d}}$ & Diameter of the hole in the die & {$[\mathrm{mm}]$} \\
$D_{\mathrm{i}}$ & Diameter of the pre-hole in the sheet & {$[\mathrm{mm}]$} \\
$D_{\mathrm{p}}$ & Diameter of the punch & {$[\mathrm{mm}]$} \\
$F_{\mathrm{p}}$ & Force acting on the punch & {$[\mathrm{N}]$} \\
$f_{\mathrm{p}}$ & Feed of the punch & {$[\mathrm{mm}]$} \\
$h_{\mathrm{c}}$ & Height of the collar & {$[\mathrm{mm}]$} \\
$l$ & Length & {$[\mathrm{mm}]$} \\
$l_{\mathrm{c}, \text { in }}$ & Developed length along the inner side of the collar & {$[\mathrm{mm}]$} \\
$l_{\mathrm{c}, \mathrm{ou}}$ & Developed length along the outer side of the collar & {$[\mathrm{mm}]$} \\
$l_{\mathrm{gap}}$ & Length of the gap between the tools during heating & {$[\mathrm{mm}]$} \\
$M_{\mathrm{s}}$ & Martensite start temperature & {$[\mathrm{K}]$} \\
$R_{\mathrm{d}}$ & Radius of the edge of the hole in the die & {$[\mathrm{mm}]$} \\
$r_{\mathrm{c}}$ & Cooling rate & {$[\mathrm{K} / \mathrm{s}]$} \\
$r_{\mathrm{h}}$ & Heating rate & {$[\mathrm{K} / \mathrm{s}]$} \\
$s$ & Thickness & {$[\mathrm{mm}]$} \\
$s_{\mathrm{c}}$ & Thickness of the collar & {$[\mathrm{mm}]$} \\
$s_{\mathrm{i}}$ & Initial thickness of the sheet & {$[\mathrm{mm}]$} \\
$\Delta \mathrm{s}_{\mathrm{c}}$ & Thinning of the collar wall & {$[\%]$} \\
$T$ & Temperature & {$[\mathrm{K}]$} \\
$T_{\gamma}$ & Austenitization temperature & {$[\mathrm{K}]$} \\
$t_{\gamma}$ & Dwell time of austenitization temperature & {$[\mathrm{s}]$} \\
$v_{\mathrm{p}}$ & Velocity of the punch & {$[\mathrm{mm} / \mathrm{s}]$} \\
$w$ & Width & {$[\mathrm{mm}]$} \\
$x$ & Distance to the water surface & {$[\mathrm{mm}]$} \\
\hline
\end{tabular}

\section{Materials and Methods}

\subsection{Process Setup and Product Properties}

For the characterization of product properties towards the realization of productoriented multivariable control, hot hole-flanging within a closed-loop controlled multistage hot sheet metal forming process with rapid heating and short dwell times in a progressive-die was assumed (Figure 1a). The sheet is pre-punched, heated by means of induction heating, and formed in several stages with simultaneous quenching by tool contact. Compared to conventional furnace heating, inductive heating of the blank inside the progressive-die extends the number of directly controllable process parameters by those of the austenitization. Actual product properties are measured after forming and, in addition to other data from the ongoing process, such as forming forces and temperature distribution, serve as input for process control. Target product properties are then set by adjusting the kinematic of the press and the austenitizing parameters. For the sake of simplicity, it was assumed that the hot hole-flanging investigated here takes place in the tool stage after the heating stage. In addition, it was presumed that the forming steps following the hot hole-flanging affect the product properties of the collar only through quenching. A superimposed strain hardening or forming of the collar in the third and fourth tool stage was therefore neglected. Similar conditions are to be expected, when a bending and a calibration operation are carried out subsequent to the hot hole-flanging.

The main geometrical product properties of the collar that are considered within the framework of control are the height of the collar $h_{\mathrm{c}}$ as well as the distribution of the wall thickness $s_{\mathrm{C}}$ and the curvature $\kappa_{\mathrm{c}}$ along the collar wall (see Figure 1b). In addition to the geometry, the hardness set by the heat treatment and forming is considered. The issues of control are addressed in [14] by taking into account an extended Kalman filter for the real-time reconstruction of the spatially and time-varying sheet temperature distribution during forming, based on suitable reduced-order process models. Here, it is shown that the interaction between forming, heat treatment, and estimated temperature evolution enables 
the reconstruction of the spatial-temporal distribution of product properties, when their control-oriented characterization is available. The latter is the topic of the present paper.

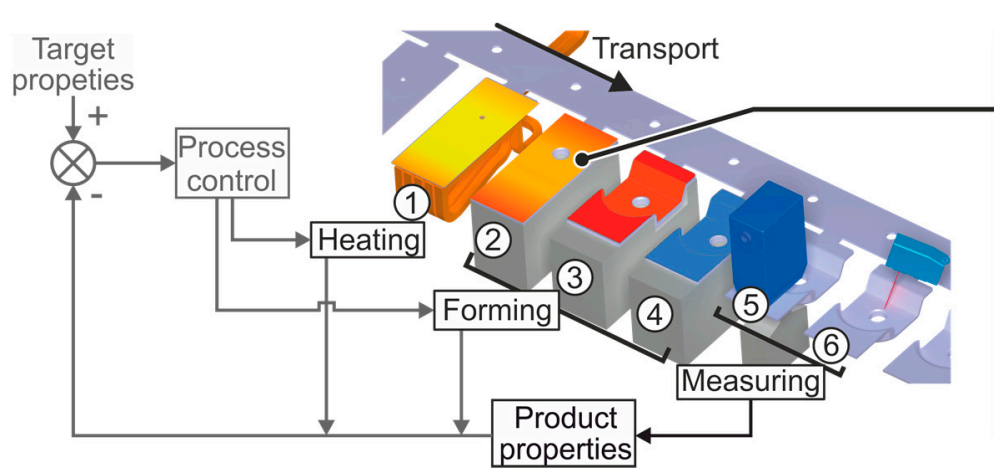

(a)

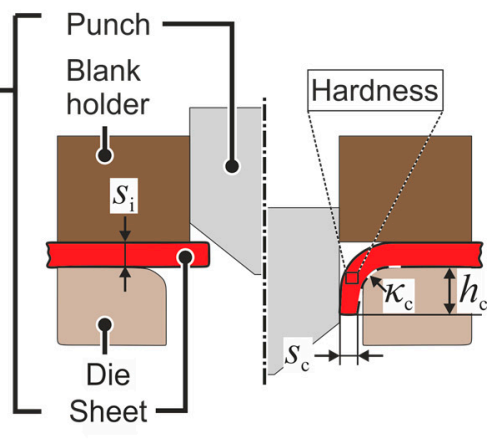

(b)

Figure 1. (a) Process design for multi-stage hot sheet metal forming in a progressive-die with a closed loop control of product properties; (b) Principle of hot hole-flanging and product properties: collar height $h_{\mathrm{c}}$, thickness of the collar $s_{\mathrm{C}}$, curvature of the collar $\kappa_{\mathrm{c}}$, and hardness.

\subsection{Material}

For the examined process, the martensitic chromium steel $\mathrm{X} 46 \mathrm{Cr} 13$ was chosen. Possible industrial applications of hardened martensitic chromium steels range from cutting blades to parts in automotive crash applications [15]. Conventional press-hardening steels (e.g., 22MnB5) require a coating or the use of inert gas serving as protection against the formation of scale during heating. Established AlSi-coatings necessitate a certain diffusion time and have a melting point below that of the base material [16]. Similar boundaries are given when using Zn-coatings [17]. Moreover, during induction heating of AlSi-coated $22 \mathrm{MnB} 5$, undesirable local accumulations of the coating layer caused by the magnetic field forces can be observed [18]. Therefore, conventionally coated press hardening steels are not suitable for heating with high heating rates $(>100 \mathrm{~K} / \mathrm{s})$ and short dwell times $(<20 \mathrm{~s})$, which is a requirement within the frame of the analyzed process. The utilization of $\mathrm{X} 46 \mathrm{Cr} 13$ allows for rapid heating within the progressive die as no coating is required, enabling an aggressive control of the austenitizing parameters as well as high stroke rates. In addition, the hardness after heat treatment of this air-hardening steel has a minor sensitivity towards the cooling rate as the critical cooling rate for obtaining a fully martensitic structure is in the order of 1.3 to $2.2 \mathrm{~K} / \mathrm{s}$ [19]. This is simplifying process control.

Experiments are carried out with heat-treated, cold-rolled X46Cr13 (DIN EN 10088-2: finish 2B) coil material. The width and sheet thickness of the coil is $200 \mathrm{~mm}$ and $2 \mathrm{~mm}$ with a tolerance according to DIN EN ISO 9445-2. To produce samples, the coil is unwound and straightened. An overview of the delivery condition is given in Table 2.

Table 2. Delivery condition of the $\mathrm{X} 46 \mathrm{Cr} 13$ coil material according to mill certificate in conformity with EN 10204/3.1.

\begin{tabular}{ccccccccc}
\hline \multirow{2}{*}{$\begin{array}{c}\text { Yield Strength } \\
\text { in MPa }\end{array}$} & Hardness & \multicolumn{6}{c}{ Chemical Composition in wt $\%$} \\
\cline { 3 - 8 } & in HV & $\mathbf{C}$ & $\mathbf{S i}$ & $\mathbf{M n}$ & $\mathbf{P}$ & $\mathbf{S}$ & $\mathbf{C r}$ & $\mathbf{F e}$ \\
\hline 372 & 245 & 0.443 & 0.37 & 0.55 & 0.026 & 0.001 & 13.76 & 84.85 \\
\hline
\end{tabular}

\subsection{Quenching Test-Heat Treatment with Rapid Heating and Short Dwell Times}

For the sole investigation of the heat treatment of the virgin $\mathrm{X} 46 \mathrm{Cr} 13$, sheet material by rapid heating and short dwell times quenching test were performed. Hereby, the heating stage of the progressive-die was emulated with an exclusion of the influence of forming on the quenched microstructure. Specimens in the form of metal strips (dimensions: $180 \mathrm{~mm} \times 20 \mathrm{~mm} \times 2 \mathrm{~mm}$ ) were heated by means of combined induction and conduc- 
tion [20] (Figure 2a) with a heating rate $r_{\mathrm{h}}$ of $\sim 1000{ }^{\circ} \mathrm{C} / \mathrm{s}$ to austenitizing temperatures $T_{\gamma}$ between $900{ }^{\circ} \mathrm{C}$ and $1100{ }^{\circ} \mathrm{C}$. $T_{\gamma}$ was held for dwell times $t_{\gamma}$ of $1,5,20$, or $300 \mathrm{~s}$ (Figure 2b). Subsequently, the specimen was quenched on one end by raising a water basin with a pneumatic actuator. The applied heating method is allowing for a rapid as well as homogenous heating. The heating device was coupled to a generator TruHeat MF7040 (TRUMPF Hüttinger, Freiburg, Germany) with an output of $40 \mathrm{~kW}$ at $600 \mathrm{~V}$ via a coaxial transformer. Depending on the distance to the water surface $x$, differing cooling rates $r_{\mathrm{c}}$ arise in the specimen. These were reversibly determined by evaluating thermal images recorded during the quenching with TIM M-1 (Micro-Epsilon Messtechnik, Ortenburg, Germany) from $1200{ }^{\circ} \mathrm{C}$ to $450{ }^{\circ} \mathrm{C}$ and VarioCam HD head $680 \mathrm{~S}$ (InfraTec, Dresden. Germany) from $450{ }^{\circ} \mathrm{C}$ to $50{ }^{\circ} \mathrm{C}$. In this investigation, the cooling rates $r_{\mathrm{c}}$ were calculated as a mean cooling rate between the austenitizing temperature and the martensite start temperature $M_{\mathrm{s}}$. Based on Yuan [21], a mean martensite start temperature $M_{\mathrm{S}}$ of $295^{\circ} \mathrm{C}$ was assumed. The austenitizing temperature and dwell time were controlled with the program Sensor Tools (Sensortherm, Sulzbach, Germany), whereby the temperature was measured by a pyrometer Metis M308 (Sensortherm, Sulzbach, Germany) focused on the center of the heated specimen. As described in Section 2.5.1, hardness measurements were carried out on the surface of the specimens generated with different parameter sets.

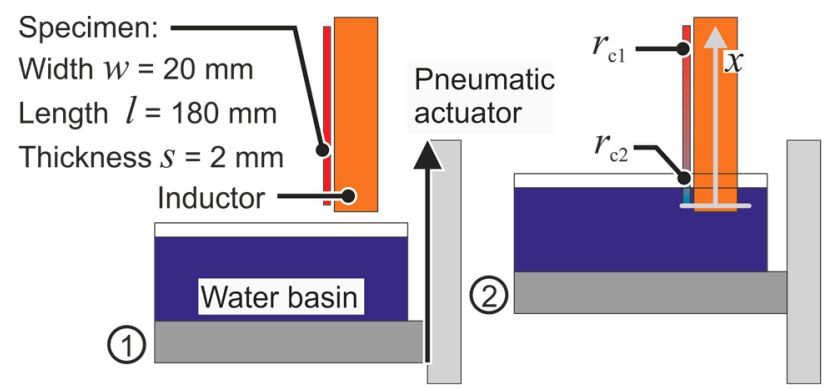

(a)

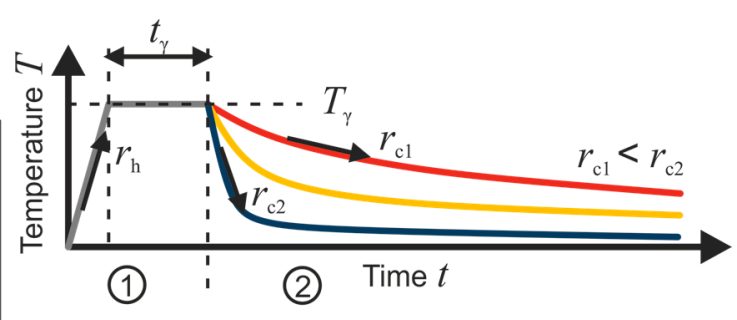

(b)

Figure 2. (a) Design of the quenching test with adjustable austenitizing temperature $T_{\gamma}$ and dwell times $t_{\gamma}$ and variating cooling rates $r_{\mathrm{c}}$ [22]; (b) Schematic time-temperature curves during heat treatment by rapid heating and short dwell times.

\subsection{Hot Hole-Flanging}

The experimental design shown in Figure 3 was deployed for emulating the heating stage and the hot hole-flanging stage in a progressive die during hot sheet metal forming. For precise setting of the lower speed range (punch velocity $v_{\mathrm{p}}$ from 5 to $10 \mathrm{~mm} / \mathrm{s}$ ), the tooling system is installed in a universal testing machine Zwick Z250 (Zwick, Ulm, Germany), also measuring the force-displacement curve during the forming process. To examine the mean and upper speed range $\left(v_{\mathrm{p}}\right.$ equal to 50 and $\left.100 \mathrm{~mm} / \mathrm{s}\right)$, the same tooling system was operated in a servo press MSD2-400 (Schuler, Göppingen, Germany). All tool elements were water-cooled and made of hardened hot work tool steel Böhler W360 (Voestalpine, Linz, Austria). Dimensions are given in Table 3.

Table 3. Characteristic values of the hot hole-flanging setup.

\begin{tabular}{cccc}
\hline ID. & Value & ID. & Value \\
\hline$\alpha_{\mathrm{p}}$ & $45^{\circ}$ & $l_{\text {gap }}$ & $20 \mathrm{~mm}$ \\
$D_{\mathrm{d}}$ & $19.1 \mathrm{~mm}$ & $R_{\mathrm{d}}$ & $2 \mathrm{~mm}$ \\
$D_{\mathrm{i}}$ & $10 \mathrm{~mm}$ & $s_{\mathrm{i}}$ & $2 \mathrm{~mm}$ \\
$D_{\mathrm{p}}$ & $14.9 \mathrm{~mm}$ & $v_{\mathrm{p}}$ & $5 \mathrm{~mm} / \mathrm{s}$ to $100 \mathrm{~mm} / \mathrm{s}$ \\
\hline
\end{tabular}




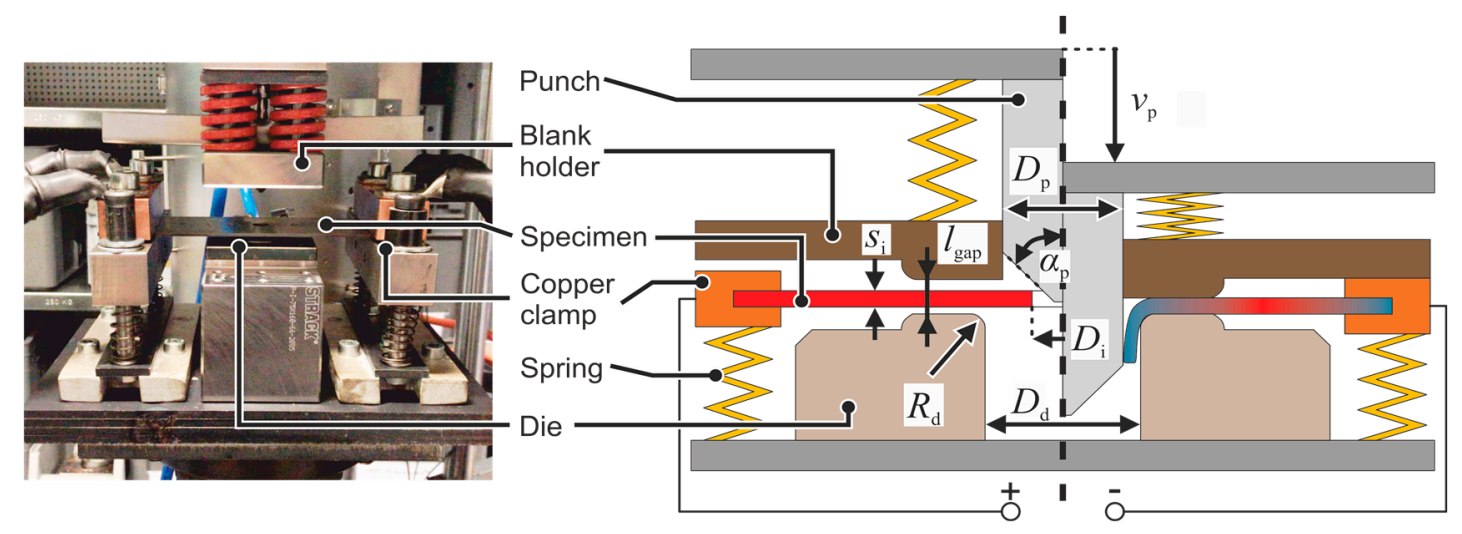

(a)

(b)

Figure 3. (a) Implementation of hot hole-flanging in a Zwick Z250 universal testing machine; (b) Schematic setup of hot hole-flanging.

First, a sheet metal plate (dimensions: $190 \mathrm{~mm} \times 60 \mathrm{~mm} \times 2 \mathrm{~mm}$ ) with a pre-hole was heated to the austenitizing temperature in $\sim 15 \mathrm{~s}$ by a DC power source with a maximum output of $44 \mathrm{~kW}$. Shorter heating times were not aimed for to avoid overheating at the edges of the pre-hole. The sheet was heated to austenitization temperatures between $900{ }^{\circ} \mathrm{C}$ and $1100^{\circ} \mathrm{C}$. After $5 \mathrm{~s}$ of dwell time, a homogeneous temperature distribution in the forming zone with a deviation of $\pm 20 \mathrm{~K}$ was observed. Then, heating was interrupted, and after a delay of $1 \mathrm{~s}$, the tool was engaged with the velocity $v_{\mathrm{p}}$. This delay emulates the transfer between the heating stage and the forming stage in the progressive-die. After reaching the bottom dead center and a holding time $t_{\mathrm{h}}$ between approximately $3 \mathrm{~s}$, the tool movement was reversed. This was intended to prevent the collar from shrinking onto the punch. In addition, the high-temperature lubricant Fenella Fluid F 505 (Houghton, Dortmund, Germany) was used to reduce the friction. Setting the heating as well as the evaluation of the temperature distribution was carried out analogously to Section 2.3. For the analysis of the influence of the preparation method of the pre-hole on thinning, curvature, and collar height during hot hole-flanging, the specimens were prepared by laser cutting as well as by drilling and reaming.

\subsection{Analysis of the Product Properties \\ 2.5.1. Hardness Measurements}

The hardness of the specimens from the quenching test was assessed directly on the flat side of the heat-treated sheet metal strips $(w \times l$ in Figure $2 \mathrm{a})$. For those specimens, hardness measurements were executed with a universal testing machine Dia Testor 2 RC (Wolpert (Buehler), Esslingen am Neckar, Germany) according to HV10 (test force 98.07 N) with a holding time of 10 to $15 \mathrm{~s}$. Three measurements were conducted for each parameter set consisting of a certain austenitizing temperature, cooling rate, and dwell time. Hot hole-flanging samples were cut orthogonal to the direction of current flow during heating (short sample side with $60 \mathrm{~mm}$ width) through the middle axis of the collar. On the cut and then polished surface, hardness tests were carried out along the inner and outer arches of the formed collars with a distance to the sheets surface of $100 \mu \mathrm{m}$. These measurements were executed according to HV0.5 (test force of $4.903 \mathrm{~N}$ ) with a holding time of $10 \mathrm{~s}$ with a Micro-Vickers-hardness tester HMV-G (Shimadzu Europa, Duisburg, Germany). The evaluation of the imprint of HV10- and HV0.5-testing from a pyramid-shaped indenter (dihedral angle of $136^{\circ}$ ) was done manually.

\subsubsection{Geometry Measurements}

The geometry of samples from hot hole-flanging was evaluated by digitizing samples with the strip light projection system Atos Triple Scan (GOM, Braunschweig, Germany) 
and assessing them within GOM Inspect (GOM, Braunschweig, Germany). The optics of the measuring system were calibrated to a measuring volume with an edge length of $170 \mathrm{~mm}$. Within GOM Inspect, 12 cutting planes running through the center axis of the digital collar at a $30^{\circ}$ angle to each other were generated. Thinning $\Delta s_{\mathrm{c}}$ of the collar was determined by calculating the distance of curves resulting from the intersection of the cutting planes with the digitized model on the inside and the outside of the collar. The evaluation of the curvature was carried out analogously to the evaluation of thinning along curves resulting from the intersection of planes with the digitized samples. To determine the collar heights, the mean distance between the surface of the everted collar edge and the lower surface of the sheet metal was measured.

\section{Results and Discussion}

\subsection{Hardness of X46Cr13 with Rapid Heat Treatment}

The hardness set by heat treatment of the $\mathrm{X} 46 \mathrm{Cr} 13$ sheet material with a variation of the austenitizing parameters at different cooling rates was examined. Only the parameter range relevant for an application in a progressive-die was analyzed with a limiting dwell time $t_{\gamma}$ of up to $20 \mathrm{~s}$ for a possible two-stage heating setup. Within the considered parameter range, the hardness can be set between 317 and 680 HV10 (Figure 4). The hardness of the heat-treated $\mathrm{X} 46 \mathrm{Cr} 13$ increases with the austenitizing temperature and dwell time. The averaged difference of the minimal and maximal hardness for cooling rates from 8 to $512 \mathrm{~K} / \mathrm{s}$ is approximately $34 \mathrm{HV} 10$. Therefore, the dependence of the hardness upon the cooling rate $r_{\mathrm{c}}$ is subordinate to that of the austenitizing temperature, underlining the air-hardening properties of the material.

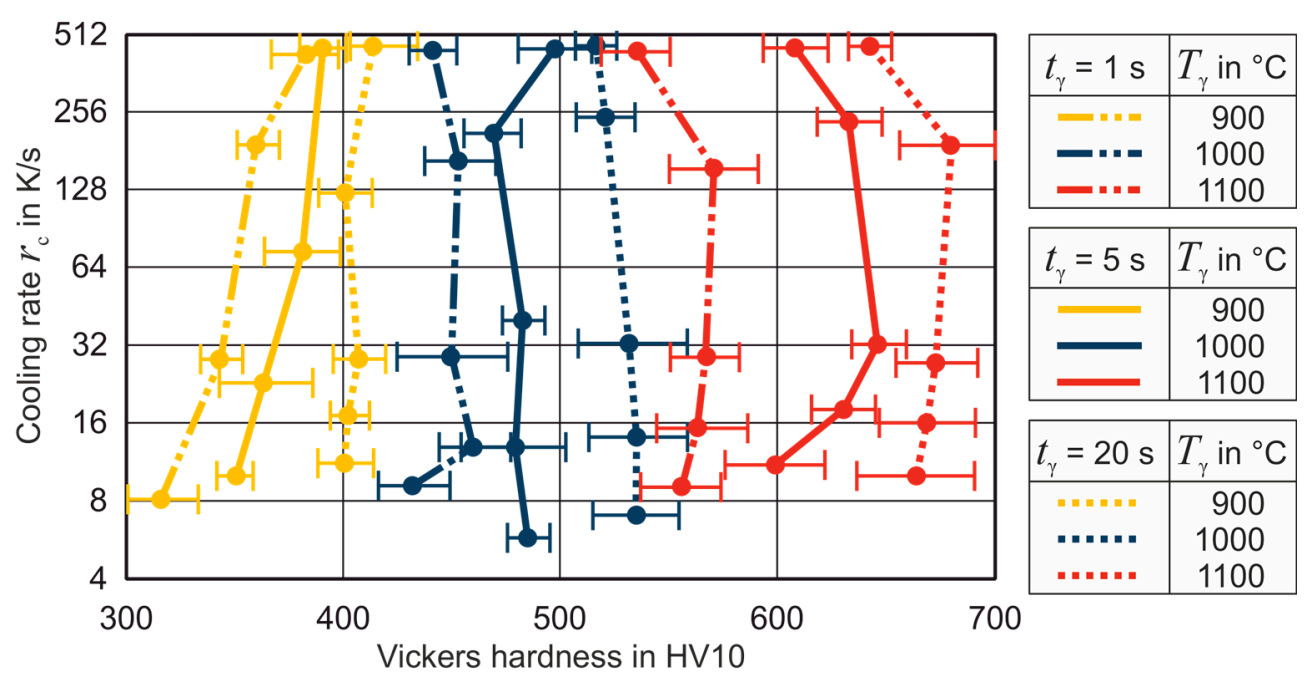

Figure 4. Hardness of $\mathrm{X} 46 \mathrm{Cr} 13$ determined from the quenching tests with variation of the austenitizing temperature $T_{\gamma}$, dwell time $t_{\gamma}$, and cooling rate $r_{\mathrm{c}}$.

According to Garcia et al. [23], who examined a constant dwell time $t_{\gamma}$ of $60 \mathrm{~s}$ and austenitizing temperatures between $1000{ }^{\circ} \mathrm{C}$ and $1250{ }^{\circ} \mathrm{C}$ for $\mathrm{X} 45 \mathrm{Cr} 13$, the increase in hardness with rising $T_{\gamma}$ can be traced back to the accompanying decrease in carbide volume fraction. Hereby, the amount of carbon dissolved in the austenite increases together with the tetragonality of the martensite after quenching, improving the final hardness. Analogously, Barlow and Du Toit [24] are describing these mechanisms for the heat treatment of the AISI 420 with a chemical composition comparable to that of $X 46 \mathrm{Cr} 13\left(t_{\gamma}\right.$ of $15 \mathrm{~min}$ and $T_{\gamma}$ between $1000{ }^{\circ} \mathrm{C}$ and $1200^{\circ} \mathrm{C}$ ). As the carbide dissolution increases, the martensite start temperature drops and the amount of residual austenite in the quenched micro-structure increases. This mechanism causes a drop in hardness when a threshold austenitizing temperature is exceeded. This threshold value of $T_{\gamma}$ decreases with rising dwell time $t_{\gamma}$ from $1120{ }^{\circ} \mathrm{C}$ at $60 \mathrm{~s}$ [23] to $1075{ }^{\circ} \mathrm{C}$ at $15 \mathrm{~min}$ [24]. To evaluate whether the mechanism 
described is the basis for the observed increase in hardness, quenching tests were also carried out with $T_{\gamma}=1100{ }^{\circ} \mathrm{C}$ and $t_{\gamma}=300 \mathrm{~s}$. Here, an average hardness of $571 \mathrm{HV} 10$ was determined, which is approximately $13 \%$ below the hardness at a dwell time of $t_{\gamma}=20 \mathrm{~s}$ (Figure 4). Accordingly, the increase in hardness at high heating rates can also be attributed to a carbide dissolution that increases with temperature and dwell time until reaching a threshold, out of range for the application in a progressive-die when $T_{\gamma}$ is limited to $1100{ }^{\circ} \mathrm{C}$.

\subsection{Forming Force and Contact Situation}

The forces acting on the punch are divided into those that occur during forming (engage) and demolding (retract) (Figure 5a). Within the displayed parameter range examined in the Zwick Z250, the austenitizing temperature $T_{\gamma}$ has a slight influence (up to $10 \%$ difference with const. $v_{\mathrm{p}}$ ) on the forming force $F_{\mathrm{p}}$. The punch speed $v_{\mathrm{p}}$ has a greater influence on the force $F_{\mathrm{p}}$ (up to $60 \%$ difference with const. $T_{\gamma}$ ). In principle, the force increases with lower forming temperatures, which can result from lower austenitizing temperatures or lower punch speeds, since the contact time with the tool and therefore the cooling time is longer here.

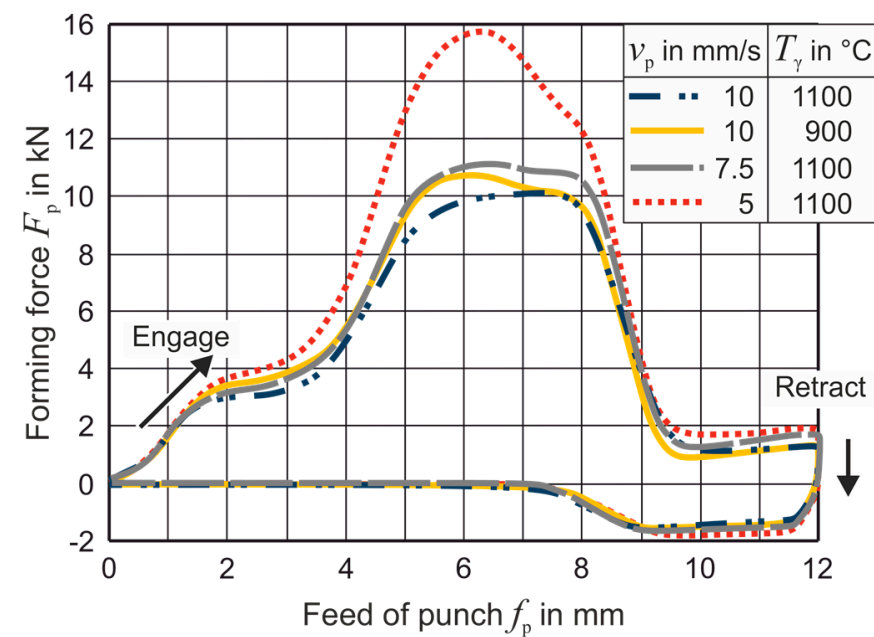

(a)

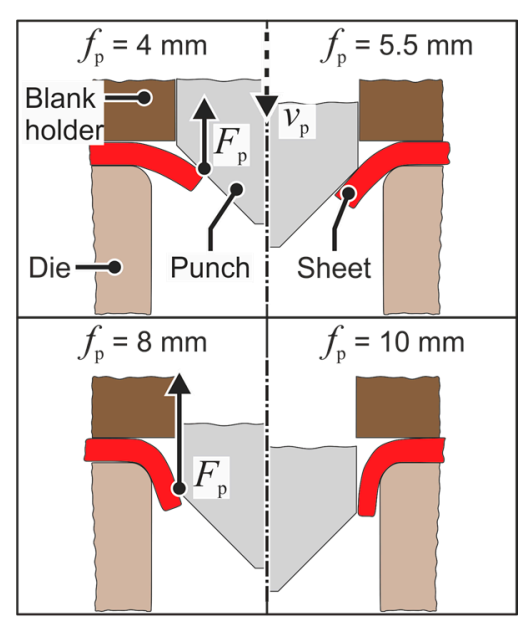

(b)

Figure 5. (a) Force acting on the punch $F_{\mathrm{p}}$ during engaging and retracting at different punch velocities $v_{\mathrm{p}}$ and austenitizing temperatures $T_{\gamma} ;(\mathbf{b})$ Schematic contact situation during forming (engaging) between sheet and punch for progressing feed $f_{\mathrm{p}}$.

The characteristics of the force-displacement curve are related to the contact situation between the sheet and the tools for progressing feed of the punch $f_{\mathrm{p}}$ (Figure $5 \mathrm{~b}$ ). After the punch comes into contact with the sheet $\left(f_{\mathrm{p}}=0 \mathrm{~mm}\right)$, the edge of the pre-hole is bent. The lever arm for bending becomes smaller with increasing feed of the punch $f_{\mathrm{p}}$, since the point of application of force moves towards the die, which results in an increase in the punch force. This matter is superimposed by the gain in forming force due to strain hardening caused by the expansion of the pre-hole. For $5.5 \mathrm{~mm}<f_{\mathrm{p}}<8 \mathrm{~mm}$, the collar is expanded around the transition between the cone and the cylindrical section of the punch. Here, a difference in shape and magnitude of the force-displacement curve at a punch speed of $5 \mathrm{~mm} / \mathrm{s}$ compared to higher punch speeds occurs. This is an indication that a phase transformation from austenite to martensite has already taken place in parts of the flange and bend area of the collar, which locally inhibits material flow. When the cylindrical punch section is pushed through the formed collar $\left(10 \mathrm{~mm}<f_{\mathrm{p}}<12 \mathrm{~mm}\right)$ and retracted, clamping forces act on the punch. These are due to the elastic springback and the thermal shrinking of the collar onto the punch. As the temperature decreases with the punch speed and the austenitizing temperature, the absolute value of clamping force 
increases during retracting of the punch. By assigning a characteristic force-displacement curve to each parameter set consisting of a temperature and a punch speed, a soft sensor can be established allowing for a reversible determination of the temperature during and after forming, subserving as input for process control.

\subsection{Geometry of the Collar}

The thinning values calculated according to Section 2.5.2 are assigned to the inner developed length $l_{c, \text { in }}$ (Figure $6 \mathrm{~b}$ ). $l_{\mathrm{c}, \text { in }}$ is set to zero at the outer edge of the contact zone between the sheet metal and the blank holder, which corresponds to a distance of $20 \mathrm{~mm}$ from the center of the collar. The collar edge $\left(l_{c, \text { in }}>16 \mathrm{~mm}\right)$ is not evaluated due to its macroscopic roughness and the associated measurement uncertainties. Thinning averaged from three samples per parameter set was analyzed dependent on the austenitizing temperature $T_{\gamma}$ (Figure 6a,c) and dependent on the punch speed $v_{p}$ (Figure 7). The average deviation of thinning calculated along the inner developed length for each parameter set is less than $\pm 1 \%$.

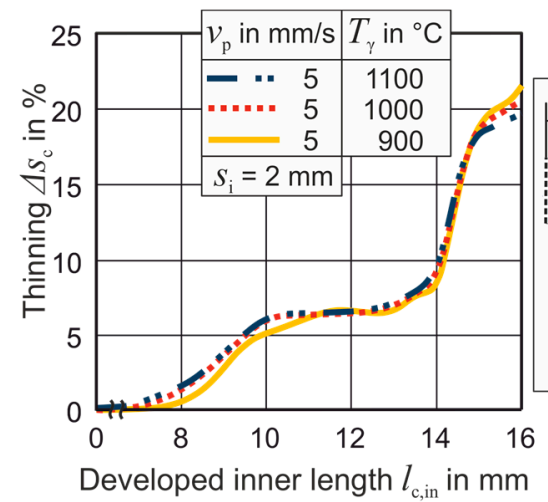

(a)

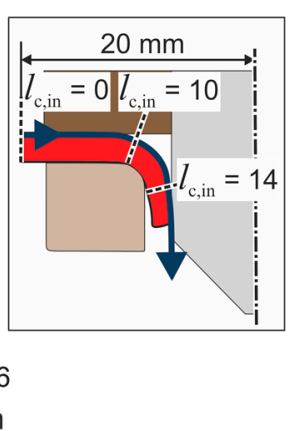

(b)

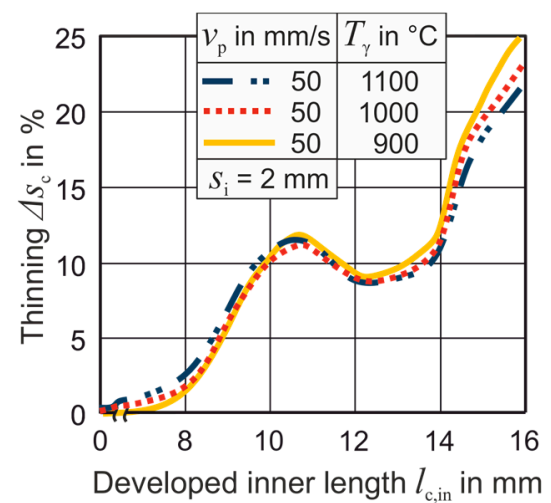

(c)

Figure 6. (a) Effect of the austenitizing temperature $T_{\gamma}$ on thinning of the collar $\Delta s_{\mathrm{c}}$ with a constant punch speed $v_{\mathrm{p}}$ of $5 \mathrm{~mm} / \mathrm{s}$; (b) Definition of the developed inner length $l_{\mathrm{c}, \text { in }}$; (c) Effect of austenitizing temperature $T_{\gamma}$ on thinning of the collar $\Delta \mathrm{s}_{\mathrm{c}}$ with a constant punch speed $v_{\mathrm{p}}$ of $50 \mathrm{~mm} / \mathrm{s}$.

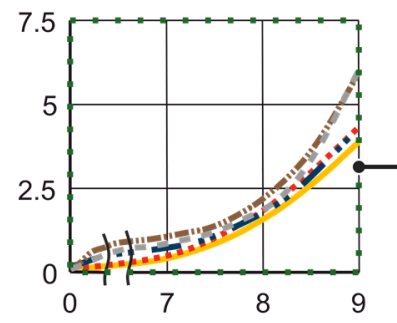

9

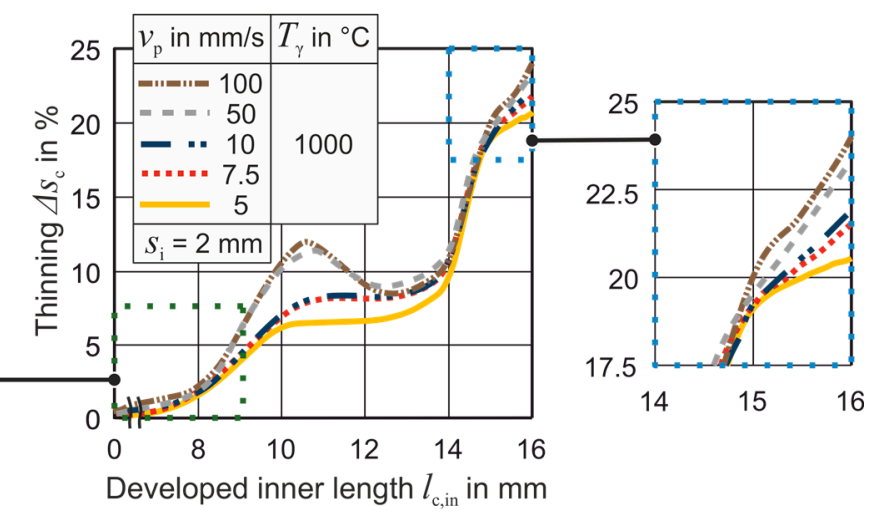

Figure 7. Effect of the punch speed $v_{\mathrm{p}}$ on thinning of collar $\Delta s_{\mathrm{c}}$ for a constant austenitizing temperature $T_{\gamma}$ of $1000{ }^{\circ} \mathrm{C}$.

Thinning of the collar flange $\left(6 \mathrm{~mm}<l_{c, \text { in }}<9 \mathrm{~mm}\right)$ is amplified with rising austenitizing temperature $T_{\gamma}$ (Figure 6) or also with rising punch speed $v_{\mathrm{p}}$ (Figure 7). The forming temperature increases with rising $T_{\gamma}$ at constant $v_{\mathrm{p}}$ or converges to $T_{\gamma}$ with rising $v_{\mathrm{p}}$, leading a reduction in flow stress, facilitating the material flow out of the flange sheet thickness. In the bend area $\left(9 \mathrm{~mm}<l_{c, \text { in }}<14 \mathrm{~mm}\right)$, thinning is affected by the increasing punch speed $v_{\mathrm{p}}$ by up to $5 \%$ (Figure 7 ). A reduction of the temperature gradient in the transition between the flange and the bend area $\left(l_{\mathrm{c}, \text { in }} \approx 9 \mathrm{~mm}\right)$ with rising punch speeds 
entails a decline in the gradient of temperature-dependent flow stress. The latter is leading to an increase of the curvature of the collar in the bend area promoting thinning. In the cylindrical collar area $\left(14 \mathrm{~mm}<l_{\mathrm{c}, \text { in }}<15 \mathrm{~mm}\right)$, thinning satisfies a linear function, showing a minor dependence of up to $2 \%$ on the set process parameters. Close to the collar edge $\left(l_{\mathrm{c}, \text { in }}\right.$ $>15 \mathrm{~mm}$ ), rising punch speeds $v_{\mathrm{p}}$ also amplify thinning (Figure 7). Inversely, for higher punch speeds of $50 \mathrm{~mm} / \mathrm{s}$, a decrease in thinning of up to $4 \%$ with increasing austenitizing temperature can be observed here (Figure 6c).

Due to the principle of volume constancy, increased thinning corresponds to a change in collar height $h_{\mathrm{c}}$ or to a change in curvature $\kappa$. A change in curvature correlates with the expansion of the pre-hole and therefore with the material flow from the sheet thickness into the circumferential direction of the collar. Within the parameter range examined in the Zwick Z250 and the Schuler MSD2-400, collar heights $h_{\mathrm{c}}$ from 3.92 to $4.09 \mathrm{~mm}$ were determined. However, with three samples being evaluated for each parameter set, the range between the determined minimal and maximal $h_{\mathrm{c}}$ is even to the scatter within a parameter set itself. Therefore, a relation between thinning and the height of the collar cannot be established. To analyze the curvature of the collar, the developed outer collar length $l_{\mathrm{c}, \mathrm{ou}}$ is considered (Figure $8 \mathrm{~b}$ ). Based on the course of the curvature along the outside of the collar $\kappa_{\mathrm{c}, \mathrm{ou}}$, the external radial expansion and convergence of the collar to the contour of the die can be concluded. Above the developed inner collar, length $l_{\mathrm{c}, \text { in }}$ is used, as it offers improved spatial resolution of thinning due to $l_{\mathrm{c}, \text { in }}>l_{\mathrm{c}, \mathrm{ou}}$. An allocation of the inner to the outer developed collar length is given in Figure $8 \mathrm{~b}$. With increasing punch speed, up to $35 \%$ greater curvatures $\kappa_{\mathrm{c} \text {,ou }}$ are set in the transition from the flange to the bend area $\left(8.5 \mathrm{~mm}<l_{\mathrm{c}, \mathrm{ou}}<10 \mathrm{~mm}\right.$ ) (Figure $\left.8 \mathrm{a}\right)$. This correlates with an increase in thinning $\Delta s_{\mathrm{c}}$ in the bend area as stated above. Due to a reduction of the equalization time with increasing punch speed, the temperature gradient within the sheet in the bending area decreases. This reduces the bending resistance in the transition area to the flange, which enables the collar to fit closer to the die contour. As the process speed increases, an up to $49 \%$ greater curvature is set in the area of the collar edge $\left(12.5 \mathrm{~mm}<l_{\mathrm{c}, \mathrm{ou}}<13.5 \mathrm{~mm}\right)$. Here, again, the reduction in the temperature gradient to the adjacent collar wall is the cause.

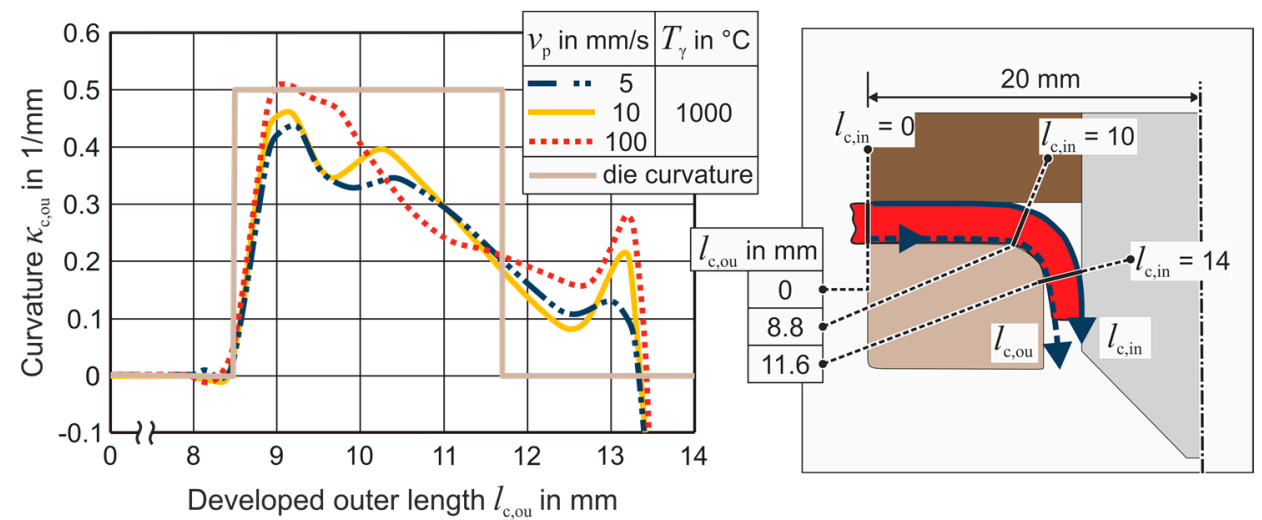

(a)

(b)

Figure 8. (a) Ideal curvature of the die and curvature $\kappa$ along the developed outer length $l_{\mathrm{c}, \mathrm{ou}}$ for different punch velocities $v_{p}$; (b) Definition of the developed outer length $l_{c, \text { ou }}$.

With a variation of the austenitizing temperature and the punch speed, no influence of thinning, curvature, and collar height upon the preparation method of the specimens during hot hole-flanging was determined. To control the examined product properties, the cutting of the pre-hole must therefore not to be considered. The presented results were determined from specimens with laser-cut pre-holes. 


\subsection{Adjusting Hardness of the Collar}

In addition to the prior investigated influence of the austenitizing temperature, dwell time, and cooling rate, the influence of forming on hardness could be present during hot hole-flanging with simultaneous heat treatment. Therefore, setting of the hardness in the formed collar was analyzed based on hardness measurements along the inside and the outside of the collar (Figure 9). For an austenitizing temperature $T_{\gamma}$ of $1100{ }^{\circ} \mathrm{C}$ with a punch speed $v_{\mathrm{p}}$ of $10 \mathrm{~mm} / \mathrm{s}$ and a dwell time $t_{\gamma}$ of $5 \mathrm{~s}$, the mean hardness in the collar is 625 HV0.5. By lowering the austenitizing temperature $T_{\gamma}$ to $900{ }^{\circ} \mathrm{C}$, the mean hardness decreases by $37.7 \%$ to 389 HV0.5, caused by a decrease in carbide dissolution (see Section 3.1). Through reduction of the punch speed $v_{\mathrm{p}}$ to $5 \mathrm{~mm} / \mathrm{s}$, the mean hardness decreases by $2.6 \%$ to $609 \mathrm{HV} 0.5$, induced by a decline of the cooling rate. On average, the hardness on the inside of the collar is $2.1 \%$ higher than on the outside. Dissimilar cooling rates over the sheet thickness in the collar are to be expected due to a differing contact situation between the tools and the inner and outer collar (see Section 3.2), which can cause the described disparity. The hardness tends to increase by an average of approximately $10 \%$ from the flange area $\left(l_{c, \text { in }}=8 \mathrm{~mm}\right)$ to the edge of the collar $\left(l_{c, \text { in }}=16 \mathrm{~mm}\right)$ (Figure 9). Analogous to Section 3.1 and as shown above based on the variation of the punch speed, this tendency cannot be attributed to a difference in cooling rate. The main cause is the sensitivity of the hardness towards a spatial variation in austenitizing temperature. The current is constricted at the edges of the pre-hole, creating a temperature gradient in the examined plane (Section 2.5.1) with a temperature range of $T_{\gamma} \pm 20 \mathrm{~K}$ and towards the edge of the pre-hole rising temperature. This is benefiting a rise of hardness towards the edge of the collar.

The deviation of the average hardness values set by combined forming and quenching compared to those set by sole heat treatment with the same austenitizing parameters is below 3\%. Accordingly, the influence of forming is neglectable and setting hardness by adapting the austenitizing parameters is also feasible for simultaneous forming and heat treatment of $\mathrm{X} 46 \mathrm{Cr} 13$ sheet material.
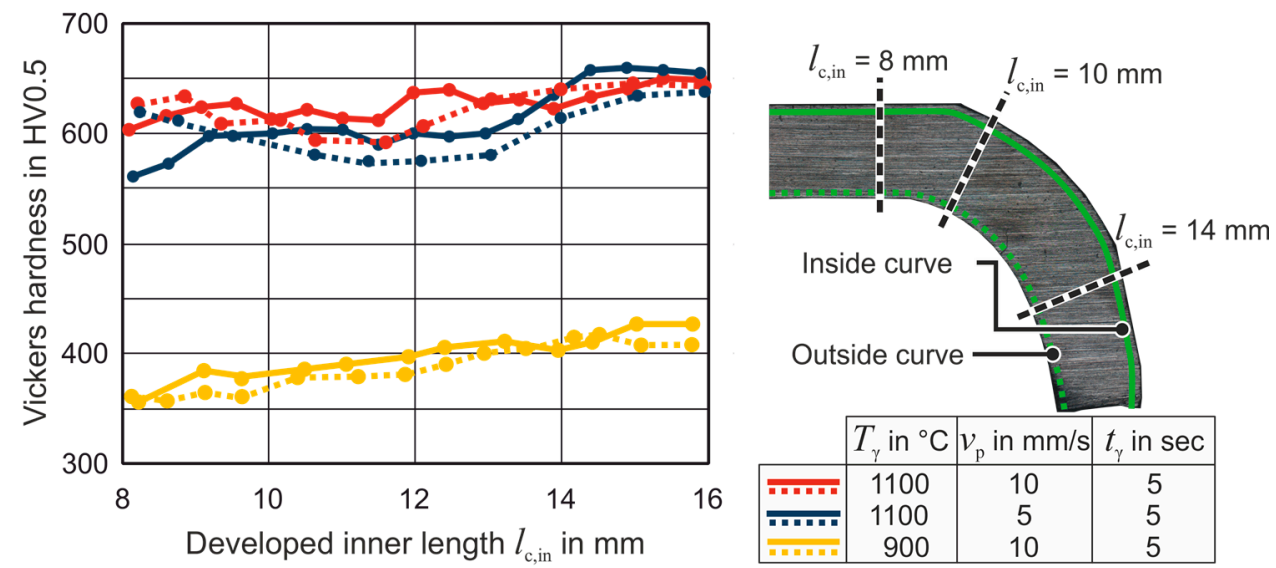

Figure 9. Distribution of hardness in the formed collar along the developed inner length $l_{\mathrm{c}, \text { in }}$ with varying austenitizing temperature $T_{\gamma}$ and punch speed $v_{\mathrm{p}}$ at a constant dwell time $t_{\gamma}$ of $5 \mathrm{~s}$.

\subsection{Control of Product Properties}

By rapid heating of the sheet metal blank inside the progressive-die with short dwell times, the austenitizing parameters in the multi-step hot sheet metal forming process can be controlled from stroke to stroke. Through adaption of the austenitizing temperature and the punch speed, the spatially as well as time-dependent temperature and cooling rate during hot hole-flanging are set. Hereby, thinning and the curvature partially are adjustable in the bend and at the outer edge area of the collar. Simultaneously, the dependency of the quenched hardness of $\mathrm{X} 46 \mathrm{Cr} 13$ sheet material on the austenitizing temperature and the dwell time and reduced sensitivity towards the cooling rate allows for a setting of 
the final product hardness during hot hole-flanging. For a more precise control of the final product hardness, the applied method for heating of the blank with the pre-hole needs to be adapted. A targeted use of several electrodes similar to Mori et al. [25], or hot cutting in same stroke with hot hole-flanging comparable to Cheng [13], is conceivable. The latter allows a blank with a constant cross-section to be heated. Based on the in-situ force measurement during hot hole-flanging, a soft sensor can be established assessing the force-displacement curves with a real-time model to determine the temperature during and after forming in the collar. The model-based soft sensor design is addressed in [14] for the considered process. Besides process and product property monitoring with this, an additional input for the process control can be generated to realize robust closed-loop property control.

\section{Conclusions}

To establish models for property-controlled multi-stage hot sheet metal forming, relationships between product properties and the process parameters must be available. As one step towards the development of fundamental approaches for property control, hot-holeflanging of $\mathrm{X} 46 \mathrm{Cr} 13$ sheet material with simultaneous heat treatment with consideration of the boundary conditions of the multi-stage process was analyzed. Hereby, relationships between the process parameters (austenitizing temperature, dwell time, punch speed) and the product properties (geometry, hardness) were derived.

An examination of the sole heat treatment of $\mathrm{X} 46 \mathrm{Cr} 13$ sheet material by means of rapid heating and short dwell times demonstrates that by adjusting the process parameters, austenitizing temperature (from 900 to $1100{ }^{\circ} \mathrm{C}$ ) and dwell time (from 1 to $20 \mathrm{~s}$ ) hardness values between 317 and $680 \mathrm{HV} 10$ are set. A minor influence of the cooling rate is determined with an average difference of $34 \mathrm{HV} 10$ between the minimal and maximal hardness for cooling rates ranging from 8 to $512 \mathrm{~K} / \mathrm{s}$. In the process window relevant for a progressive-die, the increase in hardness with rising austenitizing temperature and dwell time is traced back to an increasing dissolution of carbides into the austenite.

The analysis of the punch force in hot hole-flanging indicates the dependency upon the process parameters austenitizing temperature and punch speed with a maximum increase in force of up to $60 \%$. With this knowledge, a soft sensor can be developed, allowing for an in-situ determination of the forming parameters based on the forming force.

An evaluation of the formed geometry in hot hole-flanging at different punch speeds (from 5 to $100 \mathrm{~mm} / \mathrm{s}$ ) and austenitizing temperatures (from 900 to $1000{ }^{\circ} \mathrm{C}$ ) reveals an increase in curvature of the bend area of up to $35 \%$, correlating with an increase in thinning of up to $5 \%$. Therefore, these relationships must be considered in control.

The hardness values set during pure heat treatment are reproduced during hot holeflanging, where the influence of forming and spatially variating cooling rates is given. The minor sensitivity of the set hardness of the $\mathrm{X} 46 \mathrm{Cr} 13$ sheet material towards the cooling rate and therefore the punch speed is facilitating control of hardness during forming.

Author Contributions: Conceptualization, R.M, T.M. and A.E.T.; methodology, J.M. and D.K.; formal analysis, J.M.; investigation, J.M.; resources, T.M. and A.E.T.; writing-original draft preparation, J.M. and D.K.; writing-review and editing, R.M., T.M. and A.E.T.; visualization J.M.; supervision, R.M., T.M. and A.E.T.; project administration, J.M. and R.M.; funding acquisition, T.M. and A.E.T. All authors have read and agreed to the published version of the manuscript.

Funding: The authors would like to thank the German Research Foundation DFG for the support of the depicted research within the priority program 'SPP2183' through project no. ' 424334660 '. The financial support is greatly acknowledged.

Institutional Review Board Statement: Not applicable.

Informed Consent Statement: Not applicable.

Acknowledgments: The authors thank the German Research Foundation (DFG) for the financial support of project 424334660 in the Collaborative Research Centre SPP2183 “Property-controlled 
forming processes" (German: Eigenschaftsgeregelte Umformprozesse). Furthermore, great appreciation is extended to Tom Adams for conducting the quenching experiments as well as the hardness measurements and to Olaf Schrage as well as to Philipp Rethmann conducting the hole-flanging experiments.

Conflicts of Interest: The authors declare no conflict of interest.

\section{References}

1. Belanger, P.; Lage, M.L.; Ruiz, L.R.; Isaksson, K. New zn multi-step hot stamping innovation at gestamp. In Proceedings of the 6th International Conference Hot Steel Metal Forming of High-Performance Steel, CHS2, Atlanta, GA, USA, 4-7 June 2017; pp. 327-335.

2. Mori, K.; Maeno, T.; Sakagami, M.; Ukai, M.; Agatsuma, Y. 2-stage progressive-die hot stamping of ultra-high strength steel parts using resistance heating. Procedia Eng. 2017, 207, 681-686. [CrossRef]

3. Mori, K.; Maeno, T.; Tsuchiya, M.; Nanya, T. Inclusion of hot stamping operations in progressive-die plate forging of tailored high strength gear part. Int. J. Adv. Manuf. Technol. 2017, 90, 3585-3594. [CrossRef]

4. Bergman, G. Modelling and Simulation of Simultaneous Forming and Quenching. Ph.D. Thesis, Luleå tekniska universitet, Luleå, Sverige, 1999.

5. Neugebauer, R.; Schieck, F.; Polster, S.; Mosel, A.; Rautenstrauch, A.; Schönherr, J.; Pierschel, N. Press hardening-An innovative and challenging technology. Arch. Civ. Mech. Eng. 2012, 12, 113-118. [CrossRef]

6. Demazel, N.; Laurent, H.; Coër, J.; Carin, M.; Le Masson, P.; Favero, J.; Canivenc, R.; Salmon-Legagneur, H. Investigation of the progressive hot die stamping of a complex boron steel part using numerical simulations and Gleeble tests. Int. J. Adv. Manuf. Technol. 2018, 99, 803-817. [CrossRef]

7. Allwood, J.M.; Duncan, S.R.; Cao, J.; Groche, P.; Hirt, G.; Kinsey, B.; Kuboki, T.; Liewald, M.; Sterzing, A.; Tekkaya, A.E. Closed-loop control of product properties in metal forming. CIRP Ann. Manuf. Technol. 2016, 65, 573-596. [CrossRef]

8. Löbbe, C.; Hoppe, C.; Becker, C.; Tekkaya, A.E. Closed loop springback control in progressive die bending by induction heating. Int. J. Precis. Eng. Manuf. 2015, 16, 2441-2449. [CrossRef]

9. Löbbe, C.; Hering, O.; Hiegemann, L.; Tekkaya, A.E. Setting mechanical properties of high strength steels for rapid hot forming processes. Materials 2016, 9, 229. [CrossRef]

10. Löbbe, C.; Tekkaya, A.E. Mechanisms for controlling springback and strength in heat-assisted sheet forming. CIRP Ann. 2018, 67, 273-276. [CrossRef]

11. Groche, P.; Erhardt, R. Lasererwärmung zur Verbesserung des Umformergebnisses beim Kragenziehen von Aluminium- und Magnesiumknetlegierungen. Materwiss. Werksttech. 2004, 35, 467-472. [CrossRef]

12. Motaman, S.A.H.; Komerla, K.; Storms, T.; Prahl, U.; Brecher, C.; Bleck, W. Experimental and numerical investigation of dual phase steels formability during laser-assisted hole-flanging. In Proceedings of the 21st International ESAFORM Conference on Material Forming, Palermo, Italy, 23-25 April 2018.

13. Cheng, F.S. Hole-flange forming of high-strength steel sheet using one-step hot stamping-forging method. Proc. Inst. Mech. Eng. Part B J. Eng. Manuf. 2017, 231, 181-185. [CrossRef]

14. Klöser, D.; Martschin, J.; Meurer, T.; Tekkaya, A.E. Reduced order modelling for spatial-temporal temperature and property estimation in a multi-stage hot sheet metal forming process. Adv. Ind. Manuf. Eng. 2021. manuscript in submission.

15. Mithieux, J.-D.; Badiner, G.; Santacreu, P.-O.; Herbelin, J.-M.; Kostoj, V. Optimized Martensitic Stainless Steels for Hot Formed Parts in Automotive Crash Application. In Proceedings of the 4th International Conference Hot Sheet Meatal Forming of High-Performance Steel, CHS2 2013-Proceedings; Oldeburg, M., Prakash, B., Steinhoff, K., Eds.; Verlag Wissenschaftliche Scripten: Lulea, Sverige, 2013; pp. 57-64.

16. Suehiro, M.; Kusumi, K.; Maki, J.; Ohgami, M.; Miyakoshi, T. Properties of aluminium coated steels for hot forming. Nippon Steel Tech. Rep. 2003, 88, 16-21.

17. Da Costa Ximenes, D.A.; Moreira, L.P.; De Carvalho, J.E.R.; Leite, D.N.F.; Toledo, R.G.; Da Silva Dias, F.M. Phase transformation temperatures and Fe enrichment of a 22MnB5 Zn-Fe coated steel under hot stamping conditions. J. Mater. Res. Technol. 2020, 9 , 629-635. [CrossRef]

18. Veit, R.; Hofmann, H.; Kolleck, R.; Sikora, S. Untersuchung der Phasenbildung bei der Erwärmung Al/Si-beschichteter Formplatinen. In Proceedings of the 5 Erlanger Workshop Warmblechumformung, Erlangen, Germany, 8 December 2010; pp. 29-36.

19. Behrens, B.-A.; Hübner, S.; Sunderkötter, C.; Gebel, L.; Gnaß, S.; Berndt, G.; Trimborn, C.; Pfeffer, C. Influence of process parameters on the hot stamping of carbon-martensitic chromium steel sheets. IOP Conf. Ser. Mater. Sci. Eng. 2018, $418,012007$. [CrossRef]

20. Tekkaya, A.E.; Meya, R.; Löbbe, C. Heizvorrichtung zur Erzeugung von Joule'scher Wärme bei der Erwärmung von vorzugsweise dünnwandigen Blechteilen mittels mittelfrequentem Strom. DE102017004935.1A, 18 May 2017.

21. Yuan, L.; Ponge, D.; Wittig, J.; Choi, P.; Jiménez, J.A.; Raabe, D. Nanoscale austenite reversion through partitioning, segregation and kinetic freezing: Example of a ductile 2GPa Fe-Cr-C steel. Acta Mater. 2012, 60, 2790-2804. [CrossRef]

22. Löbbe, C. Temperaturunterstütztes Biegen und Wärmebehandeln in Mehrstufigen Werkzeugen; Shaker Verlag: Aachen, Germany, 2019; ISBN 3844064850 
23. García De Andrés, C.; Álvarez, L.F.; López, V.; Jiménez, J.A. Effects of carbide-forming elements on the response to thermal treatment of the X45Cr13 martensitic stainless steel. J. Mater. Sci. 1998, 33, 4095-4100. [CrossRef]

24. Barlow, L.D.; Du Toit, M. Effect of Austenitizing Heat Treatment on the Microstructure and Hardness of Martensitic Stainless Steel AISI 420. J. Mater. Eng. Perform. 2012, 21, 1327-1336. [CrossRef]

25. Mori, K.; Saito, S.; Maki, S. Warm and hot punching of ultra high strength steel sheet. CIRP Ann. 2008, 57, 321-324. [CrossRef] 